\title{
Surgical Mesh Implant
}

National Cancer Institute

\section{Source}

National Cancer Institute. Surgical Mesh Implant. NCI Thesaurus. Code C129507.

A surgically implanted medical device composed of woven material, often used for support of weakened or damaged organs or tissues. A surgical mesh can be used for either permanent or temporary support. 